J. Lake Sci. (湖泊科学) , 2015, 27(1): 119-127

http://www. jlakes. org. E-mail : jlakes@niglas.ac.cn

(C) 2015 by Journal of Lake Sciences

\title{
太湖典型植物氨基酸组成特征及其对水环境的影响"
}

\author{
刘 丹 $^{1}$,白画画 ${ }^{2,4}$, 朱元荣 ${ }^{2}$,林 樱 ${ }^{3}$, 吴丰昌 ${ }^{1,2 * *}$ \\ (1:河海大学环境学院,南京 210098) \\ (2: 中国环境科学研究院环境基准与风险评估国家重点实验室, 北京 100012) \\ (3:环境保护部环境工程评估中心, 北京 100012) \\ (4: 北京市环境保护科学研究院,北京 100037)
}

\begin{abstract}
摘 要: 在太湖两个不同湖区 (东太湖和贡湖) 各选择了 8 种不同类型的典型水生植物和 1 种陆生植物全株作为研究对 象,采用邻苯二甲醛柱前衍生一反相高效液相色谱法对其中 15 种氨基酸的组成特征进行了分析,并探讨了植物来源氨基 酸对湖泊水环境的影响. 结果表明东太湖区域植物体中总可水解氨基酸( THAAs) 的平均含量为 $861.6 \pm 182.96 \mu \mathrm{mol} / \mathrm{g}$, 贡湖区域植物体中 THAAs 平均含量为 $700.0 \pm 232.3 \mu \mathrm{mol} / \mathrm{g}$; 不同类型植物体中 THAAs 的含量大小依次为: 沉水植物、 浮叶植物 $>$ 挺水植物 $>$ 陆生植物; 其中天冬氨酸、谷氨酸、精氨酸、丙氨酸和赖氨酸是 THAAs 的主要组成部分, 这 5 种氨 基酸的摩尔浓度占氨基酸总量的 50\% 以上; 太湖植物中 THAAs 所含的氮元素对植物总氮的贡献在 30.7\% 94.7\% 之间， 是植物体氮元素的主要组分,也是内源氮输人的主要来源. 东太湖区域采集的植物样品中各氨基酸的浓度比例与东太湖 水体氨基酸组成差异较大,但与沉积物氨基酸组成较吻合, 表明东太湖植物来源的有机质和氨基酸是沉积物中有机质和 氨基酸的重要来源.
\end{abstract}

关键词: 太湖; 典型植物; 氨基酸

\section{Characteristics and influence to overlying water of amino acids from typical plants distrib- uted in Lake Taihu, China}

LIU Dan ${ }^{1}$, BAI Huahua ${ }^{2,4}$, ZHU Yuanrong ${ }^{2}$, LIN Ying ${ }^{3} \&$ WU Fengchang ${ }^{1,2}$

(1: College of Environment, Hohai University, Nanjing 210098, P. R. China)

(2: State Key Laboratory of Environmental Criteria and Risk Assessment, Chinese Research Academy of Environmental Sciences, Beijing 100012, P. R. China)

(3: Appraisal Center for Environment \& Engineering Ministry of Environmental Protection, Beijing 100012, P. R. China)

(4: Beijing Municipal Research Institute of Environmental Protection, Beijing 100037, P. R. China)

Abstract: The concentrations of total hydrolyzable amino acids(THAAs) were investigated in 8 kinds of typical plants of both East Lake Taihu and Gonghu Bay, in order to find the links and differences of composition of THAAs in the typical plants, sediments and water as well as the composition of THAAs in different typical plants of Lake Taihu. The form and composition of 15 kinds of THAAs in 18 samples were analyzed by o-phthalaldehyde pre-column derivatization-RP-HPLC. The average concentration of THAAs in typical plants of East Lake Taihu was $861.6 \pm 182.96 \mu \mathrm{mol} / \mathrm{g}$. The average concentration in typical plants of Gonghu Bay was $700.0 \pm 232.3 \mu \mathrm{mol} / \mathrm{g}$. The comparison of the concentrations of THAAs in different kinds of plants showed submerged macrophytes and floating-leaved macrophytes had the highest concentration of THAAs, followed by emerged macrophytes and terrestrial plants. The dominating amino acids were Asparagine, Glutamic acid, Arginine, Alanine and Lysine, which accounted for more than $50 \%$ of concentration of THAAs. About $30.7 \%-94.7 \%$ of the $\mathrm{N}$ in plants were from THAAs, which was an important source of $\mathrm{N}$ in plants. Meanwhile, in comparison with the composition of THAAs in sediments and water in Lake Taihu, the typical plants generally aligned with sediments but different from the water. It showed that THAAs in plant may be an important source of

* 国家自然科学基金项目(41130743)资助. 2014-03-10 收稿;2014-05-19 收修改稿. 刘丹(1989 ), 女, 硕士;Email:liudanld0621@163.com.

** 通信作者;E-mail:wufengchang@ vip. skleg. cn. 
the THAAS in sediments.

Keywords: Lake Taihu; typical plants; amino acids

太湖是我国典型的大型浅水湖泊, 水生植物是其生态系统重要组成部分且是湖泊内源有机质的重要来 源之一 ${ }^{[1]}$. 水生植物可分为挺水植物、沉水植物、浮叶植物和浮游植物 4 种 ${ }^{[2]}$, 在太湖沿岸带广泛分布 ${ }^{[3]}$. 这 些水生植物具有水体产氧、参与氮循环、吸附沉积物、抑制浮游藻类繁殖、减轻水体富营养化、提高水体自净 能力等重要功能 ${ }^{[2,4]}$. 然而, 自 1970s 开始, 太湖水质开始逐步恶化, 1980s 湖泊水体开始出现富营养化并频 繁暴发蓝藻水华 ${ }^{[5]}$. 对于营养盐过剩的湖泊生态系统而言, 湖泊区域的陆生和水生植物调谢衰亡后, 植物残 体在湖泊内的分解会造成湖泊水体的二次污染 ${ }^{[4,6]}$. 尤其是太湖典型的草型湖区一一东太湖沉积物中的有 机物质主要来源于水生植物 ${ }^{[7]}$.

氨基酸是生态系统中生命物质生长的物质基础和基本组分之一 ${ }^{[8]}$, 同时也是湖泊水体和沉积物中有机 质的重要组成部分, 在湖泊生态系统营养物质的生物化学循环过程中扮演着十分重要的角色 ${ }^{[6]}$. 湖泊中营 养物质 (碳、氮和磷等) 的循环过程往往与有机质密切相关 ${ }^{[9-12]}$, 而有机质中氨基酸的含量变化和组成特征 的差异可以很好地指示有机质的来源和降解特征 ${ }^{[13]}$. 近年来, 国内外学者开展了对海洋中颗粒物 ${ }^{[14-15]}$ 、溶解 性有机物 ${ }^{[16-17]}$ 、沉积物 ${ }^{[13]}$ 、河流和湖泊水体中颗粒物 ${ }^{[16,18-19]}$ 的氨基酸的分析与研究. 已有研究表明不同介质 中有机质发生降解转变时, 总水解氨基酸 (THAAs) 也随之改变. 随着颗粒物粒径的减小 ${ }^{[14-15]}$ 、水深的增 加 ${ }^{[16-17]}$ 和沉积物老化程度的增加 ${ }^{[13]}$, 有机质降解程度增加而 THAAs 的浓度将减小. 某些单个氨基酸组分含 量亦随着有机质降解程度的变化而发生变化, 如亮氨酸、异亮氨酸、苯丙氨酸、酪氨酸、谷氨酸含量随着有机 质降解程度的增加而下降, 而甘氨酸、丝氨酸、苏氨酸的含量则相反 ${ }^{[13]}$. 尤其, D 型氨基酸与 $\mathrm{L}$ 型氨基酸的比 值大小可以表示氨基酸的来源 ${ }^{[16]}$. 因此, 对太湖水生植物氨基酸的组成特征及其差异的研究分析对于进一 步了解湖泊生态系统氮循环和有机质归趋等具有重要的意义.

太湖水体 ${ }^{[20-21]}$ 和沉积物 ${ }^{[22]}$ 中的氨基酸组成特征等的研究已表明太湖溶解性氨基酸主要是内源输人,同 时氨基酸也是太湖沉积物中有机质和有机氮的重要组成部分. 太湖生态系统中典型陆生和水生植物是内源 输人的重要来源. 然而, 对这些典型植物中氨基酸组成特征的研究尚未见报道, 尤其是植物中氨基酸含量与 太湖水体及沉积物中氨基酸来源的关系. 因此, 本研究选取并采集了广泛分布于太湖的 8 种优势水生植物 和 1 种陆生植物, 分析各植物体中氨基酸的含量和组成特征, 对比不同植物来源氨基酸的组成特征, 并进一 步与太湖沉积物、水体中氨基酸组成特征进行对比. 旨在揭示不同类型植物之间氨基酸组成特征的差异,分 析植物来源的有机质和氨基酸对湖泊水体和沉积物中有机质和氨基酸的贡献.

\section{1 材料与方法}

\section{1 样品采集与制备}

2011 年 8 月在东太湖和贡湖各采集 1 种陆生植物和 8 种优势水生植物全株样品 $5 \sim 10$ 株 $^{[3]}$. 陆生植物 样品为狗尾巴草 (Setaria); 水生植物样品包括菱 (Trapa)、狐尾藻 (Myriophyllum)、荇菜 (Nymphoides peltatum) 、黑藻 (Hydrilla) 、眼子菜 (Potamogeton)、芦苇(Phragmites adans)、萃草 (Zizania)、分枝苶 (Polygonum). 样品采集后经洗净晾干并置于 $105^{\circ} \mathrm{C}$ 烘箱中杀青 ( $15 \mathrm{~min}$ ), 然后进一步风干、研磨备用. 利用元素分析仪 (Vario macro E1, Germany) 测定典型植物体内基本元素组成特征, 包括氮 $(N)$ 、碳 $(\mathrm{C})$ 、硫 $(\mathrm{S})$ 、氢 $(\mathrm{H})$ 的含 量. 经测定, 东太湖水体总氮、总磷浓度分别为 $0.99 、 0.03 \mathrm{mg} / \mathrm{L}$, 贡湖水体总氮、总磷浓度分别为 1.51 、 $0.05 \mathrm{mg} / \mathrm{L}$.

\section{2 试剂和材料}

氨基酸标准样品: 由于脯氨酸无法用邻苯二甲醛( OPA) 衍生, 半胱氨酸无法被 FLD 检测器吸收, 色氨酸 在酸水解过程中被破坏, 本研究中的总水解氨基酸只测定了另外 15 种氨基酸. 因此, 购买氨基酸标准样品 包括天冬氨酸 (Asp)、谷氨酸 ( Glu )、丝氨酸 ( Ser)、丙氨酸 ( Ala) (质量分数 $\geqslant 98 \%$, SIGMA 试剂公司), 组氨

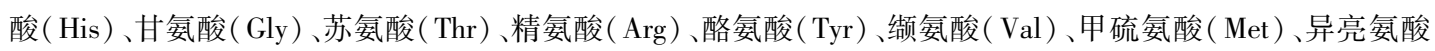
(Ile)、苯丙氨酸 (Phe)、亮氨酸 ( Leu)、赖氨酸 ( Lys) (质量分数 $\geqslant 98 \%$, 阿拉丁试剂公司). 称取适量氨基酸标 
准样品, 溶于 $0.09 \mathrm{~mol} / \mathrm{L} \mathrm{HCl}$ 溶液中, 配制成浓度为 $0.6 \mathrm{mmol} / \mathrm{L}$ 的混标溶液备用.

衍生剂: $0.3 \mathrm{~mol} / \mathrm{L} \mathrm{OPA}$ (分析纯, SIGMA) $\beta$-颈基乙醇 (分析纯, SIGMA) 甲醇体积比 $1: 4$ 溶液, $5 \mathrm{~h}$ 内 使用.

缓冲溶液: 硼酸 $(0.5 \mathrm{~mol} / \mathrm{L})$ 与氢氧化钾 $(0.5825 \mathrm{~mol} / \mathrm{L})$ 混合配制的缓冲溶液 $(\mathrm{pH}=10.4)$.

\subsection{THAAs 的分析测定}

准确称取 $100 \mathrm{mg}$ 样品于安鶕管中, 加人 $10 \mathrm{ml} 6 \mathrm{~mol} / \mathrm{L}$ 盐酸溶液, $100 \mu \mathrm{l} 12 \mathrm{mmol} / \mathrm{L}$ 抗坏血酸水溶液, 充氮气烧结封管, 移人 $110^{\circ} \mathrm{C}$ 恒温箱中水解 $22 \mathrm{~h}$, 取出冷却, 中断水解过程. 取 $1 \mathrm{ml}$ 上清液, 用 $6 \mathrm{~mol} / \mathrm{L}$ 氢 氧化钠水溶液中和,过 $0.45 \mu \mathrm{m}$ 滤膜, 处理后的样品溶液保存待分析. 准确吸取 $300 \mu \mathrm{l}$ 处理后的样品溶 液, 加人 $300 \mu \mathrm{lOPA}$ 衍生剂和 $400 \mu \mathrm{l}$ 缓冲溶液, 充分混匀, 再次利用 $0.45 \mu \mathrm{m}$ 滤膜过滤, 溶液置于 $2 \mathrm{ml}$ 样 品瓶中, 衍生 15 min 后采用高效液相色谱仪 (Agilent 1200 ) 配备荧光检测器 (Agilent G1314BFLD) 进行分 析测定.

色谱分析条件:LiChrospher $100 \mathrm{RP}-18$ 色谱柱 $(250 \mathrm{~mm} \times 4.6 \mathrm{~mm}, 5 \mu \mathrm{m})$; 流动相 $\mathrm{A}: 25 \mathrm{mmol} / \mathrm{L}$ 醋酸钠水 溶液 $(\mathrm{pH}=5.8)$ : 四氢呋喃 $=95: 5(\mathrm{~V}: \mathrm{V})$, 摇匀, 过 $0.45 \mu \mathrm{m}$ 滤膜; 流动相 $\mathrm{B}$ : 甲醇; 流速: $1.0 \mathrm{ml} / \mathrm{min}$; $\mathrm{Em}=$ $340 \mathrm{~nm}, \mathrm{Ex}=450 \mathrm{~nm}$; 进样量: $10 \mu \mathrm{l}$. 梯度洗脱程序为 $0 、 12 、 20 、 22 、 31 、 35 、 40 、 50 、 52 、 60 \mathrm{~min}$ 时, 流动相 $\mathrm{A}$ 的比 例分别为 $90 \% 、 72 \% 、 70 \% 、 65 \% 、 63 \% 、 53 \% 、 45 \% 、 35 \% 、 90 \% 、 90 \%$.

\section{4 样品中氨基酸含量的计算与数据分析}

在上述样品前处理和高效液相色谱分析的条件下,60 min 内各种氨基酸可被完全分离. 15 种氨基酸利 用标准样品色谱峰保留时间定性,外标法定量. 空白基质加标方法测定样品前处理方法的回收率如下: 丝氨 酸为 $75.1 \% \pm 5.7 \%$,丙氨酸为 $75.7 \% \pm 4.5 \%$, 蛋氨酸为 $58.2 \% \pm 21.7 \%$, 其它氨基酸的平均回收率在 $80 \%$ 98\% 之间,相对标准偏差在 $4.8 \%$ 以下. 最后结果经空白扣除和回收率校正.

运用 R2.15.2 软件进行组间差异的参数检验, $P>0.05$, 表示为未达到显著检验水平, $0.01<P<0.05$ 为显著水平, $P<0.01$ 为极显著水平. 运用 Matlab 7.9 软件进行异常值检验.

\section{2 结果与讨论}

\section{1 太湖典型植物中元素组成特征}

东太湖与贡湖植物体中 $\mathrm{C}$ 平均含量分别为 $39.0 \%$ 和 $38.5 \%$ (图 1a), 这是由于含有较高含量 $\mathrm{C}$ 元素的 糖类、脂类和蛋白质等是构成植物生命体的基础物质. 氮元素是蛋白质、核酸和磷脂等植物生长发育所必需 化合物的重要构成部分, 东太湖与贡湖植物的 $\mathrm{N}$ 平均含量为 $24.8 \%$ 和 $21.7 \%$ (图 1b). 另外, 硫元素是植物 含硫蛋白质 (如胱氨酸、半胱氨酸、甲硫氨酸) 的组成元素, 其平均含量为 $0.5 \%$ (图 $1 \mathrm{~d}$ ). 对于不同湖区而言, 同类型的植物中 $\mathrm{C} 、 \mathrm{~S} 、 \mathrm{H}$ 的平均含量差别很小 (图 1 a 、 c 、d). 但是, 对比分布于东太湖的植物和贡湖植物中 $\mathrm{N}$ 的平均含量, 表明东太湖植物体中 $\mathrm{N}$ 平均含量较高. 其中, 来源于东太湖浮叶植物、挺水植物以及陆生植物 的 $\mathrm{N}$ 平均含量均大于贡湖 (图 1b). 这可能是由于东太湖的无机氮浓度适合植物等生长发育, 进而促进了植 物对 $\mathrm{N}$ 的吸收 ${ }^{[23]}$. 对比研究发现沉水植物中碳含量较低,这可能是由于 $\mathrm{CO}_{2}$ 作为植物中的 $\mathrm{C}$ 源, 其它 3 种植 物可通过直接光照并吸收大气中 $\mathrm{CO}_{2}$ 通过光合作用充分利用 $\mathrm{C}$, 而沉水植物的光照强度弱和受水体中 $\mathrm{CO}_{2}$ 来源的限制, 对 $\mathrm{C}$ 的利用受到一定程度的影响 ${ }^{[24]}$; 由于陆生植物只能通过地下部分根系吸收 $\mathrm{S}$ 元素, 而水生 植物还可以通过地上部分茎叶从水体中吸收利用 $S$ 元素 ${ }^{[25]}$, 因此,陆生植物的含硫量较低.

\section{2 太湖典型植物体中 THAAs 的含量与组成特征}

太湖不同湖区水生植物中 THAAs 含量及各氨基酸的相对摩尔百分含量见表 1. 东太湖水生植物体中 THAAs 的含量介于 $544.5 \sim 1137.0 \mu \mathrm{mol} / \mathrm{g}$ 之间, 平均含量为 $861.6 \pm 182.96 \mu \mathrm{mol} / \mathrm{g}$; 贡湖水生植物体中 THAAs 的含量在 $366.8 \sim 1082.5 \mu \mathrm{mol} / \mathrm{g}$ 之间变化, 平均含量为 $700.0 \pm 232.3 \mu \mathrm{mol} / \mathrm{g}$. 分析不同类型植物表 明, 来源于东太湖的浮叶植物、沉水植物、挺水植物和陆生植物的平均 THAAs 含量分别为 952.7、878.2、 675.7 和 $528.6 \mu \mathrm{mol} / \mathrm{g}$; 来源于贡湖的 4 种类型植物的平均 THAAs 含量分别为 829.6、877. 1、547. 4 和 $366.8 \mu \mathrm{mol} / \mathrm{g}$. 统计分析结果表明东太湖植物样品的 THAAs 含量显著高于贡湖样品 $(P<0.05)$ (图 2). 富营 养化水体在很大程度上不利于水生植物的生长, 水中过高的 N、P 可能会对植物产生胁迫作用 ${ }^{[26]}$. 贡湖富营 
养化程度较高, 其水体总氮、总磷、氨氮均大于东太湖 ${ }^{[27]}$. 因此, 与贡湖相比, 东太湖环境更利于植物的生长, 从而促进氨基酸合成.
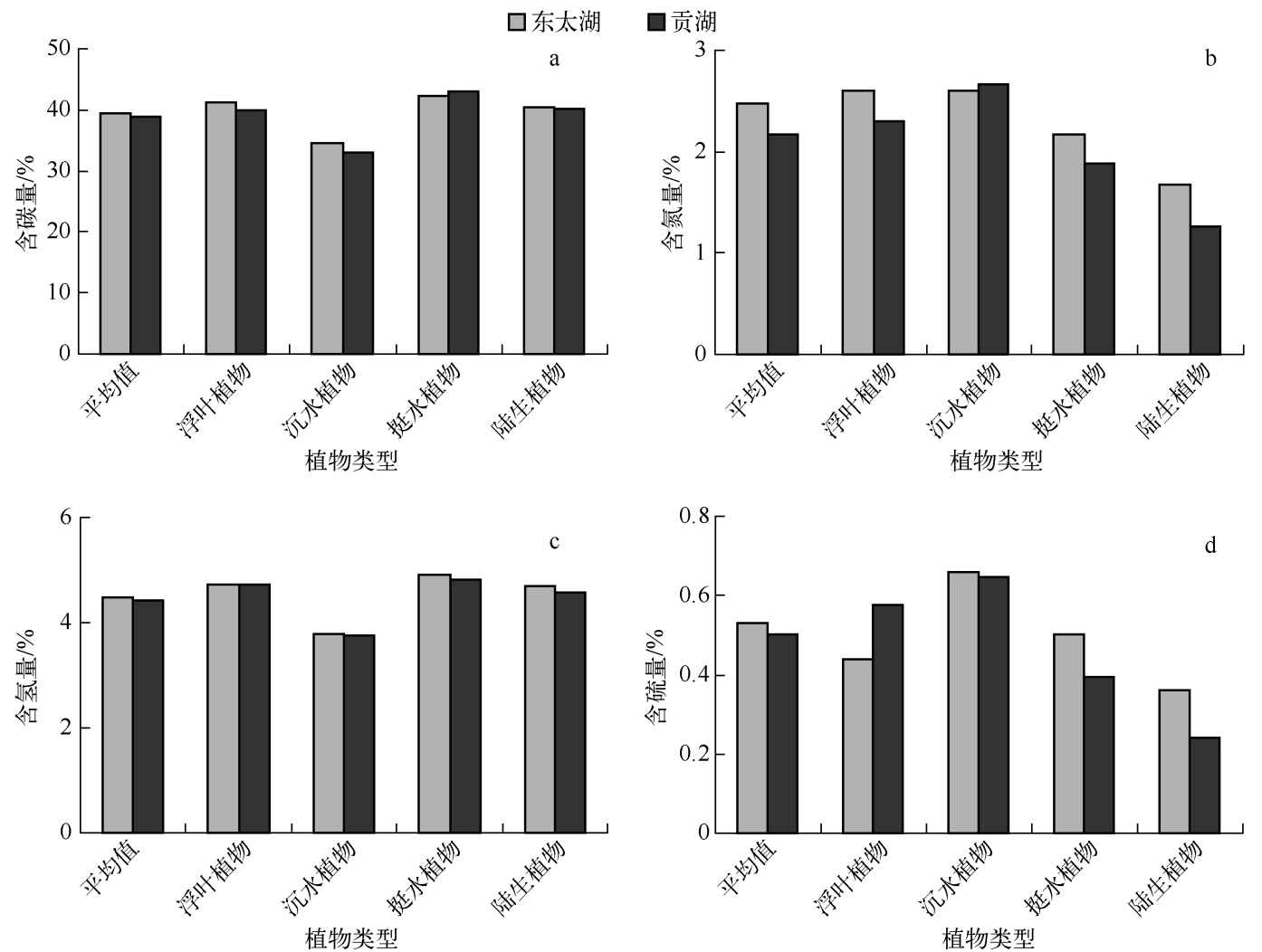

图 1 太湖不同植物中 $\mathrm{C} 、 \mathrm{~N} 、 \mathrm{H} 、 \mathrm{~S}$ 组成

Fig. 1 Compositions of C, N, H, S in typical plants from Lake Taihu

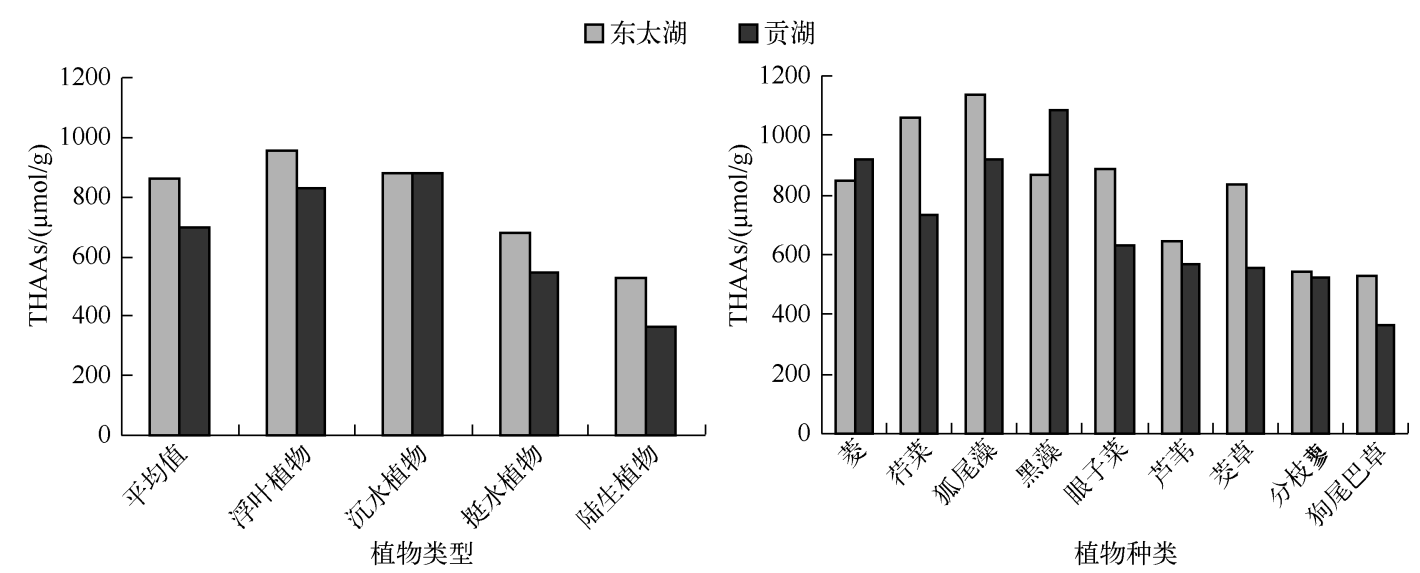

图 2 不同植物 THAAs 含量

Fig. 2 Total concentrations of THAAs in typical plants

东太湖各类植物 THAAs 含量大小依次为浮叶植物 $>$ 沉水植物 $>$ 挺水植物 $>$ 陆生植物, 而贡湖为沉水植 物 $>$ 浮叶植物 $>$ 挺水植物 $>$ 陆生植物. 这基本遵循沉水植物、浮叶植物 $>$ 挺水植物 $>$ 陆生植物的规律, 表明 


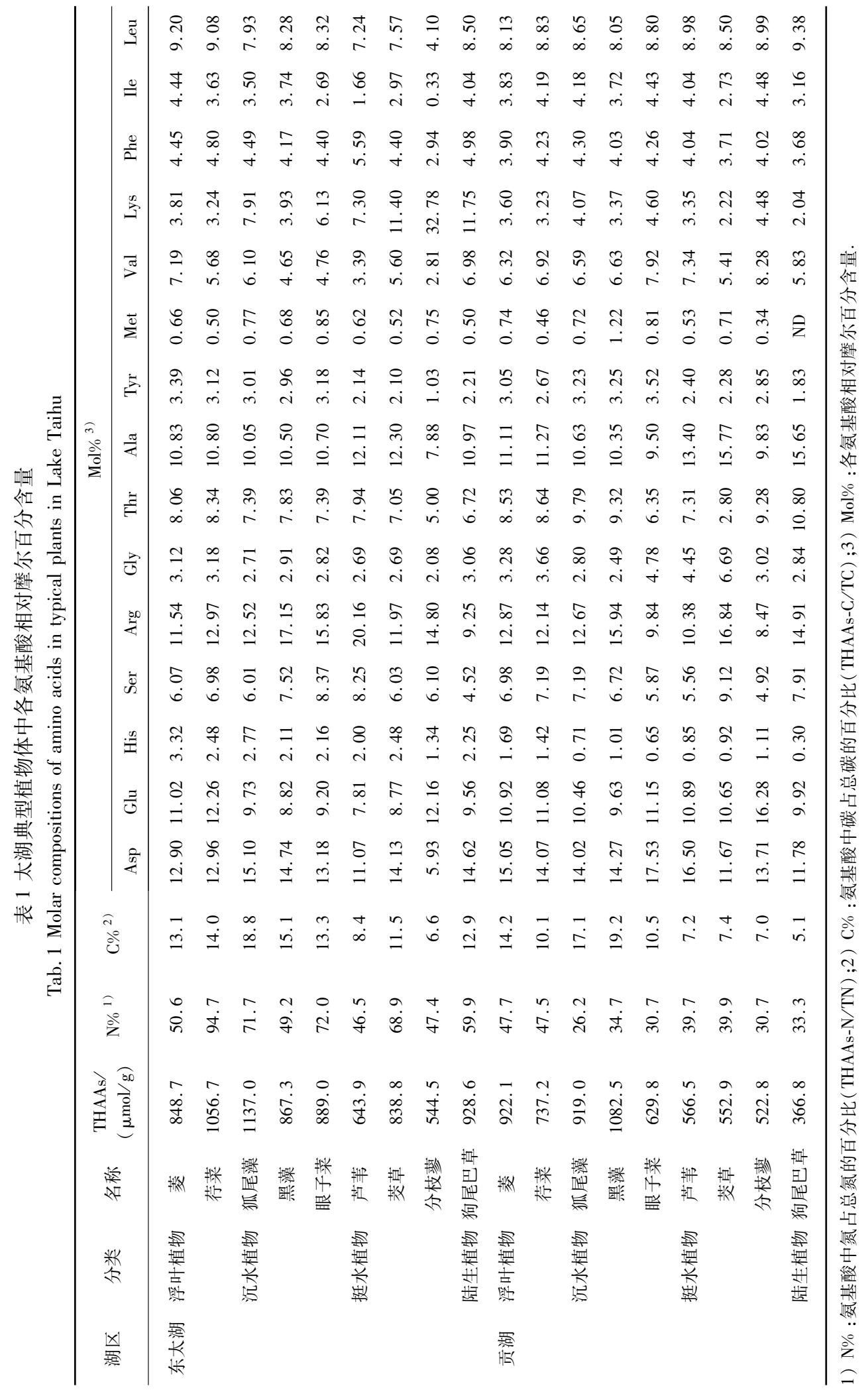


植物体内的 THAAs 含量既与水体沉积物等外在环境有关, 又与植物的生长形态相关 ${ }^{[26]}$. 沉水植物从营养物 质丰富的沉积物和底层水体中吸收营养物质; 浮叶植物主要通过巨大叶片从水面吸收营养物质, 也可以通 过根系从沉积物中吸收营养物质; 挺水植物主要利用根系吸收营养物质, 通过茎运输到水上部分. 两个湖区 中水生植物体的 THAAs 含量均大于陆生植物, 表明水生植物中氨基酸的含量相对较高, 与水生植物总氮含 量大于陆生植物一致, 已有的研究报道也表明 ${ }^{[28]}$, 与陆生植物相比, 水生植物体内蛋白质含量更高.

太湖植物体中 Glu、Ala、Lys、Arg 和 Asp 的摩尔百分比均大于 $10.0 \%$ ，其总和可达 THAAs 的 50. $0 \%$ 以 上, 是植物氨基酸的主要组成部分. Lys 、His $\operatorname{Arg}$ 的氨基数目大于羧基, 属于碱性氨基酸; Glu、Asp 则相反, 属 于酸性氨基酸; 其余属于中性氨基酸. 其中, 东太湖植物的碱性氨基酸、酸性氨基酸和中性氨基酸的平均摩 尔百分比依次为 $26.1 \% 、 22.6 \%$ 和 $51.3 \%$, 而贡湖这 3 类氨基酸平均摩尔百分比分别为 $17.1 \% 、 25.5 \%$ 和 $57.4 \%$. 结果表明中性氨基酸为植物体中氨基酸主要类型, 东太湖植物碱性氨基酸含量高于酸性氨基酸, 贡 湖则相反. 研究分析的 15 种植物氨基酸中, 难降解的 Ser、Ala 和 Lys 浓度比较高, 易于富集 ${ }^{[20]}$, 东太湖和贡 湖植物这 3 种氨基酸的平均比例之和分别为 $27.2 \%$ 和 $22.2 \%$. 与其他介质的研究对比, 表明不同来源有机 质中 Ser/ (Ser + Ala + Lys ) 具有差异性. 湖泊水生植物中 Ser/ ( Ser + Ala + Lys) 的变化范围为 13. 2\% $35.2 \%$, 平均值为 $28.4 \%$. 陆生维管束植物中变化范围为 $25.6 \% \sim 35.6 \%$, 平均值为 $26.3 \%$; 海洋浮游植物 中变化范围为 $12.9 \% \sim 21.8 \%$, 平均值为 $18.8 \%$; 浮游动物中均值为 $16.7 \%$, 在 $15.1 \% \sim 19.4 \%$ 间变化; 细 菌平均值为 $16.2 \%$, 其变化范围为 $12.3 \% \sim 20.1 \%{ }^{[29]}$; 淡水硅藻中平均值为 $50.3 \%$, 变化范围为 $41.2 \% \sim$ $63.2 \%{ }^{[30]}$. 综合分析表明, 太湖水生植物中 Ser/ ( Ser + Ala + Lys) 值与陆生维管束植物较接近, 而与海洋浮 游植物、浮游动物、细菌、硅藻中的 Ser/ (Ser + Ala + Lys) 值有差异.

\section{3 太湖典型植物体中 THAAs-N/TN、THAAs-C/TC 分析}

氨基酸中的碳( THAAs-C) 和氮( THAAs-N) 对 TC 和 TN 的贡献比例分别介于 5.1\% 19.2\% 和 $30.7 \% \sim$ 94.7\% 之间. 较高的 THAAs-N/TN 表明植物体中的氮大多以生物可利用性氨基酸氮的形式存在, 是太湖生 态系统中氮营养元素的重要来源之一. 东太湖不同类型植物 THAAs-C/TC 大小依次为沉水植物 $>$ 浮叶植物 $>$ 陆生植物 $>$ 挺水植物; THAAs-N/TN 大小依次为浮叶植物 $>$ 沉水植物 $>$ 挺水植物 $>$ 陆生植物. 贡湖植物中 THAAs-C/TC 值大小依次为: 沉水植物 $>$ 浮叶植物 $>$ 挺水植物 $>$ 陆生植物; THAAs-N/TN 值依次为浮叶植 物 $>$ 挺水植物 $>$ 陆生植物 $>$ 沉水植物. 其中, 东太湖狐尾藻中氨基酸碳所占比例最大 (18.8\%), 荇菜中氨基 酸氮所占比例最大 $(94.7 \%)$.

不同类型植物的各种氨基酸中氮在总氮中所占的比例也存在差异 (图 3), 其中 $\mathrm{Arg}$ 中 $\mathrm{N}$ 占总氮的平均 值达到 $15 \%$ 以上, 这是由于 $\operatorname{Arg}$ 的摩尔浓度在所有氨基酸中相对较大, 且 1 个 Arg 分子中含有 6 个氮原子, 是 15 种氨基酸中含有氮原子最多的氨基酸之一, 因此 $\mathrm{Arg}$ 对氮的贡献最大. 而易分解的 Phe、Glu 等 ${ }^{[20]}$ 所占 比例也较大, 东太湖和贡湖这 3 种氨基酸 $\mathrm{N}$ 比例的总和分别为 $27.8 \%$ 和 $24.3 \%$. 另外, 难降解的 Ser、Ala、 Lys 这 3 种氨基酸中的 $\mathrm{N}$ 比例在东太湖和贡湖来源的植物样品中分别为 $13.5 \%$ 和 $8.2 \%$, 这部分氨基酸易 于沉积.

\section{4 太湖典型植物、沉积物和水体中氨基酸比例特征对比分析}

东太湖植物样品与沉积物表层 $(0 \sim 3 \mathrm{~cm})^{[22]}$ 氨基酸浓度与 THAAs 浓度比例关系的对比见图 4. 经过对 植物样品与沉积物样品中的各氨基酸比例异常点检验, 得出二者 Gly、Arg、Asp 组成差异较大, 剩余 11 种氨 基酸比例具有显著的相关性 $(P<0.05)$. 东太湖沉积物中 Ser/ ( Ser + Ala + Lys ) 的变化范围为 $19.8 \% \sim$ $27.8 \%$, 平均值为 $24.8 \%$. 这与水生植物的比值较接近, 表明东太湖广泛分布的植物可能是沉积物中氨基酸 的主要来源 ${ }^{[22,31-33]}$. 植物来源的有机质和氨基酸进人沉积物后, 与其他来源的氨基酸相混合, 在微生物等作 用下进行降解和转化, 使得 Arg、Asp 比例减小, 而 Gly 的比例增加. 氨基酸组成特征可以用来指示有机质在 湖泊生态系统中的降解程度 ${ }^{[13,34]}$. Dauwe 等 $^{[13]}$ 在研究有机质降解过程中表明单个氨基酸含量随着降解程 度的变化而发生变化, 如 Leu、Ile、Phe、Tyr、Glu 含量随有机质新鲜度减小而下降, 与之相反, Gly、Ser、Thr 的 含量则随之增加. 与沉积物样品相比, 植物样品中的 Leu、Phe、Tyr、Glu 含量相对较大, 而 Gly、Ser 却相反. 这 可能表明植物是沉积物中有机质和氨基酸的重要来源之一. 植物来源的有机质和氨基酸输人湖泊沉积物 后, 在微生物等作用下新鲜程度减小, 降解程度增加. 

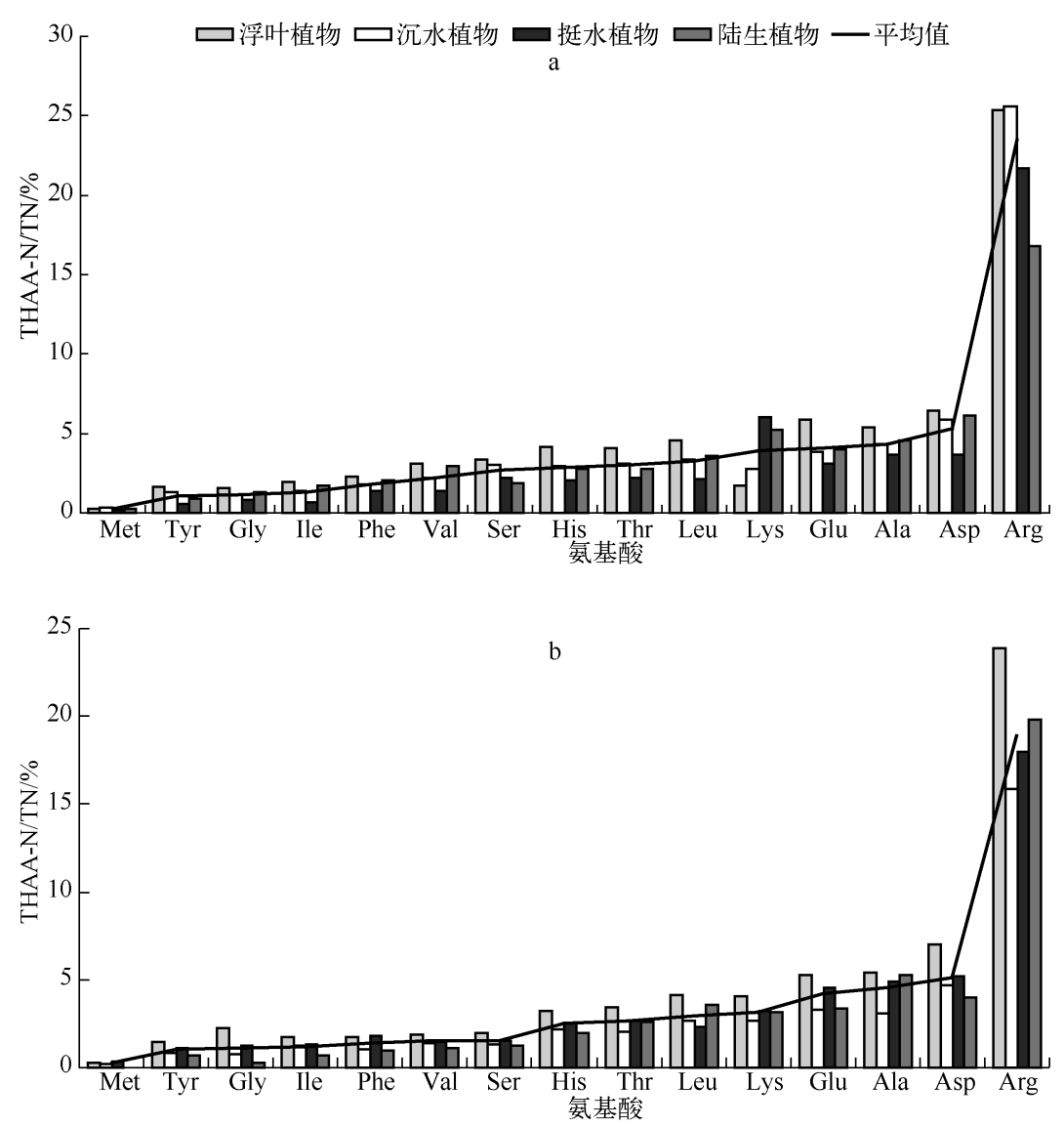

图 3 东太湖 (a) 和贡湖 (b) 不同类型植物氨基酸氮与植物总氮的比例

Fig. 3 THAAs-N/TN in typical plants of East Lake Taihu(a) and Gonghu Bay(b)

与太湖水体中氨基酸组成特征 ${ }^{[21]}$ 的比较, 表明植物来源的 His、Ile、Ser、Glu 的比例与水体中的较相似 (图 4). 对植物和水体氨基酸比例进行异常值检验, 表明二者的 Lys 比例差异较大,其余氨基酸比例没有显 著相关性 $(P>0.05)$. 同时, 东太湖水体中 Ser/ $(\mathrm{Ser}+\mathrm{Ala}+\mathrm{Lys})$ 值的变化范围可达 $4.3 \% \sim 31.1 \%$, 平均值为 $16.2 \%$, 且不同点位水体差别较大. 这表明太湖周边河流氨基酸类营养盐的输 ${ }^{[35]}$ 和湖泊水体中氨基酸本 身较易降解和转化 ${ }^{[20]}$ 导致了植物和水体中氨基酸组成特征的差异.

综合比较表明植物来源的有机质和氨基酸是湖泊沉积物中有机质和氨基酸的重要来源, 这些有机质在 微生物等作用下参与湖泊中营养物质的生物地球循环,尤其是植物来源有机质中总可水解氨基酸可能对湖 泊中氮生物地球化学循环具有重要的作用 ${ }^{[36]}$.

\section{3 结论}

太湖典型植物体中的氨基酸含量变化依次为沉水植物、浮叶植物 $>$ 挺水植物 $>$ 陆生植物, 其中东太湖 植物样品中的氨基酸含量大于贡湖中的植物样品. 其中, 天冬氨酸、谷氨酸、精氨酸、丙氨酸、赖氨酸的摩尔 百分比占到总量的 $50 \%$ 以上,是 THAAs 主要组成部分. 植物氨基酸中碳元素占到总碳的 $5.1 \% \sim 19.2 \%$, 而 植物氨基酸中氮元素是总氮的主要组成部分, 占总氮的 30.7\% 94. 7\%, 是太湖内源氮营养元素的主要来 源. 太湖生态系统中广泛分布的典型植物来源的有机质和氨基酸是沉积物中有机质和氨基酸的重要内源 输人. 


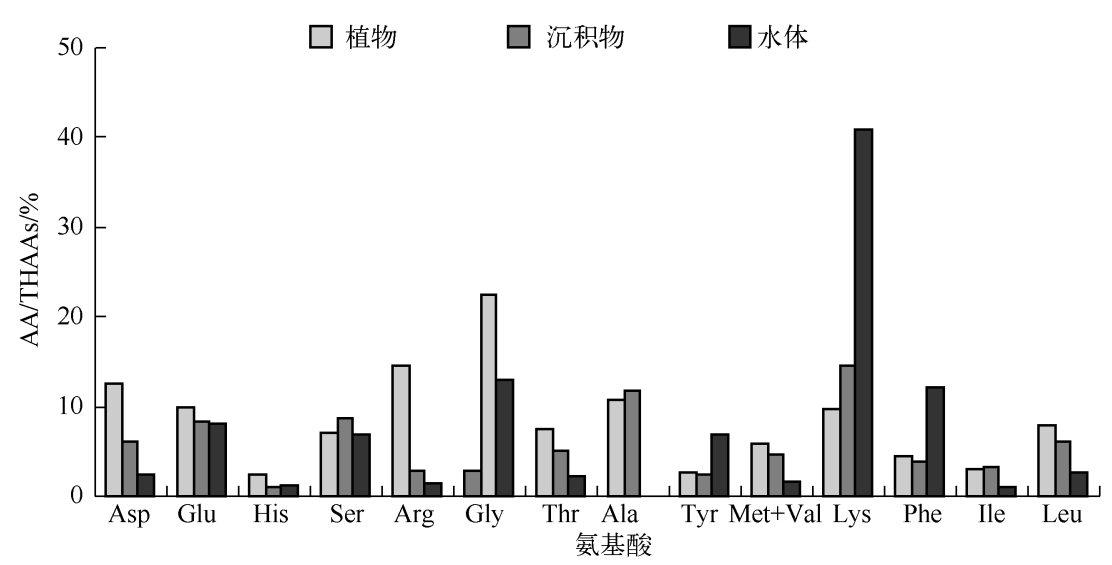

图 4 东太湖植物、沉积物 ${ }^{[22]}$ 和水体 ${ }^{[21]}$ 中各氨基酸在 THAAs 中的相对比例 (引用数据中 Met 与 $\mathrm{Val}$ 合并, 本图中表示为 Met $+\mathrm{Val}$ )

Fig. 4 Differences of AA/THAAs in sediment, water and typical plants in East Lake Taihu

\section{4 参考文献}

[1] 何 俊, 谷孝鸿, 刘国锋. 东太湖水生植物及其与环境的相互作用. 湖泊科学, 2008,20(6):790-795.

[2] 李冬林,王 磊,丁晶晶等. 水生植物的生态功能和资源应用. 湿地科学, 2011,9(3) :290-296.

[ 3 ] 2008 年太湖健康状况报告. 水利部太湖流域管理局,2008.

[ 4 ] 杨清心. 东太湖水生植被的生态功能及调节机制. 湖泊科学, 1998,10(1):67-72.

[ 5 ] 颜昌宙, 许秋瑾, 赵景柱等. 五里湖生态重建影响因素及其对策探讨. 环境科学研究, 2004,17(3):44-47.

[6] Davis J, Kaiser K, Benner R. Amino acid and amino sugar yields and compositions as indicators of dissolved organic matter diagenesis. Organic Geochemistry, $2009, \mathbf{4 0}(3)$ : 343-352.

[ 7 ] 李文朝. 东太湖水生植物的促淤效应与磷的沉积. 环境科学, 1997,18(3):9-12.

[8] 王华静,吴良欢,陶勤南. 高等植物氨基酸生物效应的研究进展. 土壤通报,2004,34(5):469-472.

[9] 吴丰昌,王立英,黎 文等. 天然有机质及其在地表环境中的重要性. 湖泊科学,2008,20(1):1-12.

[10] Wu FC, Mills RB, Evans RD et al. Kinetics of metal-fulvic acid complexation using a stopped-flow technique and threedimensional excitation emission fluorescence spectrophotometer. Analytical Chemistry, 2004 ,76 (1) :110-113.

[11] Wu FC, Cai YR, Evans D et al. Complexation between $\mathrm{Hg}(\mathrm{II})$ and dissolved organic matter in stream waters: an application of fluorescence spectroscopy. Biogeochemistry, $2004,71(3): 339-351$.

[12] 吴丰昌,金相灿,张润宇等. 论有机氮磷在湖泊水环境中的作用和重要性. 湖泊科学,2010,22(1):1-7.

[13 ] Dauwe B, Middelburg JJ. Amino acids and hexosamines as indicators of organic matter degradation state in North Sea sediments. Limnology and Oceanography, 1998,43(5):782-798.

[14] Davis J, Benner R. Seasonal trends in the abundance, composition and bioavailability of particulate and dissolved organic matter in the Chukchi/Beaufort Seas and western Canada Basin. Deep Sea Research Part II: Topical Studies in Oceanography, $2005, \mathbf{5 2}(24): 3396-3410$.

[15] Kaiser K, Benner R. Biochemical composition and size distribution of organic matter at the Pacific and Atlantic time-series stations. Marine Chemistry, $2009, \mathbf{1 1 3}(1): 63-77$.

[16] Kaiser K, Benner R. Major bacterial contribution to the ocean reservoir of detrital organic carbon and nitrogen. Limnology and Oceanography, $2008, \mathbf{5 3}(1): 99$.

[17] Dittmar T, Fitznar HP, Kattner G. Origin and biogeochemical cycling of organic nitrogen in the eastern Arctic Ocean as evident from D- and L-amino acids. Geochimica et Cosmochimica Acta, 2001,65(22):4103-4114.

[18 ] Tremblay L, Benner R. Organic matter diagenesis and bacterial contributions to detrital carbon and nitrogen in the Amazon River system. Limnology and Oceanography, 2009,54(3):681-691. 
[19] Jørgensen NO, Stepanaukas R, Pedersen AU et al. Occurrence and degradation of peptidoglycan in aquatic environments. FEMS Microbiology Ecology, 2003 ,46(3):269-280.

[20] 姚 昕,朱广伟,秦伯强. 太湖北部水体溶解性氨基酸分布特征及其环境意义. 中国环境科学, 2010,30(10): 1402-1407.

[21] 姚 昕,朱广伟,高 光等.太湖水体溶解性氨基酸的空间分布特征. 生态学报,2013,33(18):5402-5407.

[22] Yao X, Zhu G, Cai L et al. Geochemical characteristics of amino acids in sediment of Lake Taihu, a large, shallow, eutropic freshwater Lake of China. Aquatic Geochemistry, 2012,18(3):263-280.

[23] 张贵龙,赵建宁, 刘红梅等. 不同水生植物对富营养化水体无机氮吸收动力学特征. 湖泊科学, 2013,25 (2): 221-226.

[24] 苏睿丽. 沉水植物光合作用的特点与研究进展. 植物学通报,2005,22 (增刊) : 128-138.

[25] 武维华. 植物生理学. 北京:科学出版社,2008:96-112.

[26] 雷泽湘,徐德兰,谢贻发等. 太湖水生植物氮磷与湖水和沉积物氮磷含量的关系. 植物生态学报, 2008,32(2): 402-407.

[27] 太湖健康报告. 水利部太湖流域管理局,2011.

[28］杨柳燕,张 奕, 肖 琳等. 固体发酵提高水生植物发酵产物蛋白含量的研究. 环境科学学报,2007,27(1):35-39.

[29] Cowie GL, Hedges JI. Sources and reactivities of amino acids in a coastal marine environment. Limnology and Oceanography, $1992,37(4): 703-724$.

[30 ] Hecky R, Mopper K, Kilham P et al. The amino acid and sugar composition of diatom cell-walls. Marine Biology, 1973, 19(4):323-331.

[31] 王金权, 刘金玲. 太湖沉积物中氨基酸及其有机质的垂直分布与古生态意义. 微体古生物学报, 1994,11 (2): 249-257.

[32] Qin B, Xu P, Wu Q et al. Environmental issues of lake Taihu, China. Hydrobiologia, 2007,581(1) :3-14.

[33] Meyers PA, Teranes JL. Sediment organic matter. Tracking Environmental change using lake sediments: Physical and geochemical methods. Dordrecht: Springer Netherlands, $2002: 239-269$.

[34] 陈建芳,张海生,金海燕等. 北极陆架沉积碳埋藏及其在全球碳循环中的作用. 极地研究,2004,16(3):193-201.

[35] 陈小锋,揣小明, 曾 巾等. 太湖氮素出人湖通量与自净能力研究. 环境科学, 2012,33(7):2309-2314.

[36] 李文朝. 东太湖沉积物中氮的积累与水生植物沉积. 中国环境科学, 1997,17(5):418-421. 